\title{
Jogos digitais na apropriação de conhecimentos científicos
}

\author{
André Gustavo Schaeffer - Universidade Federal da Fronteira Sul - Campus Erechim \\ andre_schaeffer@uffs.edu.br \\ José André Perez Angotti - PPGECT - UFSC \\ zeangotti@gmail.com
}

\begin{abstract}
Resumo: o presente artigo aborda o uso de jogos eletrônicos para fins de ensino e de aprendizagem voltados à apropriação de conhecimentos científicos. Reflete um pouco sobre a conceituação de aprendizagem baseada em jogos digitais segundo Marc Prensky, e analisa dois exemplos de jogos atualmente sendo usados para este fim: o qCraft, complemento do jogo Minecraft para iniciação aos conceitos da teoria quântica $e$ o Foldit, um jogo colaborativo para criação de modelos tridimensionais de estruturação de proteínas.
\end{abstract}

Palavras-chave: gamificação; projeto foldit; minecraft; aprendizado baseado em jogos.

Abstract: the present paper discusses the use of electronic games for teaching and learning directed to the appropriation of scientific knowledge. Reflects a little about the conceptualization of digital games based learning according to Marc Prensky, and analyzes two examples of games currently being used for this purpose: qCraft, a complement for the game Minecraft intended to be used for initiation to the concepts of quantum theory, and Foldit, a collaborative game to create three-dimensional models for structuring proteins.

Keywords: gamification; foldit project; minecraft; games based learning.

\section{Introdução}

Em meados da segunda guerra mundial, a inteligência militar britânica esforçava-se para decodificar mensagens secretas enviadas pelos nazistas às suas tropas por ondas de rádio. O objetivo era óbvio: se isso fosse possível, saberia-se com antecedência quais as intenções e estratégias do comando nazista que estariam sendo planejadas, o que permitiria aos britânicos evitar ataques e planejar ações de guerra que pudessem conduzi-los à vitória. Mas a decodificação de mensagens criptografadas, com a tecnologia da época, não era tarefa fácil. Era preciso trabalhar em grupo. Um dos personagens envolvidos nesses trabalhos, o matemático Alan Turing, já lotado em Bletchley Park, um dos centros de inteligência militar inglês à época, precisou lançar mão de um processo urgente de seleção de pessoas para complementar sua equipe de trabalho. Essas pessoas precisariam ter boa capacidade de resolução de problemas voltados a quebra de códigos, pensamento lógico não convencional e raciocínio matemático diferenciado. Mas como saber onde poderiam ser encontradas naquele país pessoas com tamanho talento, e que não fossem somente bons, e sim, os melhores? A solução encontrada foi a realização de um processo de recrutamento um tanto quanto inusitado: a impressão de um desafio de palavras cruzadas impresso no jornal britânico The Daily Telegraph com instruções convidando a quem quer que conseguisse encontrar sua solução, em determinado e curto período de tempo, a entrar em contato para concorrer a uma oportunidade de emprego vinculada ao governo britânico. Essa solução 
utilizada nada mais foi do que o uso de um jogo, aparentemente despretensioso e sob a forma de um desafio, para avaliar quais dos interessados teriam o melhor potencial para o importante trabalho que viria a seguir. Prensky (2007) reconhece o potencial de processos para fins de aprendizagem baseados em desafios lúdicos. $\mathrm{O}$ autor entende que não somente jogos eletrônicos em computador ou vídeo game podem ser usados com propósitos de aprendizagem. É natural que o uso de tecnologia facilita a aceitação e a execução de processos dessa natureza, mas não é imprescindível que se use tecnologia ou redes de comunicação para que, segundo o autor, crie-se um processo contextualizado de aprendizado baseado em jogos.

O presente artigo abordará, inicialmente, os conceitos de aprendizagem baseada em jogos, evoluindo para a abordagem das formas atuais de uso de jogos voltadas para a aquisição de conhecimentos científicos. Mais especificamente, serão apresentadas as estratégias que cientistas têm usado com vistas a disseminar os conceitos da teoria quântica e da complexa estrutura química que compõe as proteínas, assuntos de enorme importância para o avanço da ciência mas que encontram fortes barreiras para serem transpostos didaticamente a ponto de poderem ser ensinados. Este artigo, assim delimitado, não abordará questões igualmente importantes inerentes ao mundo do jogos digitais, como a banalização da violência, dependência, e desconexão com a realidade, fatores estes com consequências ainda não completamente conhecidas, estudadas nos campos da pedagogia e da psicologia.

\section{2. $O$ aprendizado baseado em jogos digitais}

O aprendizado baseado em jogos digitais representa uma forma de aprender motivadora diferentemente de outras formas que raramente o são. Mas não é a única forma de aprender e nem funciona de maneira isolada. Tampouco representa a solução para todos os problemas de aprendizado diariamente enfrentados. Combinado com métodos que promovem interação entre o instrutor e seus aprendizes ou entre aprendizes com seus pares, pode ter sua potencialidade aumentada. Ou seja, deve ser combinado com outras formas e métodos de aprendizagem igualmente eficazes. Não existem, porém, fórmulas mágicas padronizadas de desenvolvimento de processos de aprendizado baseados em jogos. Felizmente, há sim uma grande variedade de formas de se chegar a isso. Mas infelizmente, esse grande número de formas existentes é devido à grande necessidade de contextualização que o processo exige. E isso vai depender do público-alvo, do assunto, da tecnologia disponível, e da experiência e do conhecimento prévios desse público-alvo. Ainda, o tipo de interatividade que o jogo terá deve estar de acordo com o tipo de conteúdo que se deseja aprender. Prensky (2007) sinaliza que o aprendizado baseado em jogos digitais, apesar de ser mais frequentemente associado a processos educativos dentro de escolas, é extensível a universidades e ambientes corporativos, podendo alcançar e afetar públicos mais amplos, como pessoas envolvidas com processos criativos no mundo do entretenimento, artistas ou mesmo indivíduos responsáveis por treinamentos militares. Segundo Prensky, o aprendizado baseado em jogos digitais pode ser aplicado, por razões estratégicas, aos próprios consumidores e/ou fornecedores de uma empresa. É claro que isso tem forte relação com interesses 
comerciais e estratégias de marketing da empresa interessada. Com esse entendimento, até mesmo um quiz direcionado a um consumidor que visita o web site da empresa pode ser enquadrado como uma forma de aprendizado baseado em jogos, ainda que em sua forma mais simples. Isso é possível uma vez que considera aspectos como conteúdo e contex to do quiz como critérios de enquadramento.

O aprendizado baseado em jogos digitais, como não poderia deixar de ser, aparece com maior naturalidade na promoção de artigos manufaturados da própria indústria da informática. Prensky (2007) reporta um caso em que dispositivos eletrônicos como assistentes pessoais digitais seriam exemplos de insucesso comercial devido à dificuldade que os próprios consumidores teriam ao lidar com suas interfaces. A solução para isso? Um jogo! O desafio proporcionado por um jogo presente no próprio dispositivo acabava por desenvolver habilidades manuais e perceptivas do jogador que também seria o próprio interessado no aparelho, e que por vezes até já o possuia, reduzindo ou até eliminando a dificuldade inicialmente encontrada em sua operação.

Há que se reconhecer que existem casos de aprendizado baseado em jogos que agregaram muito valor ao negócio de empresas, ao promover engajamento de equipes de trabalho, fidelização de clientes e conhecimento de perfis de consumidores. Também é sabido que os jogos digitais são desafiadores e promovem com facilidade o envolvimento e o trabalho em equipe do público ao qual são direcionados. Porém, deve ser levado em conta que a promoção de algum tipo de aprendizagem baseada em jogos digitais demanda muita criatividade e esforço. Além disso, não surpreende o fato de que muitas soluções apresentadas em Prensky (2007) e enquadradas como aprendizagem baseada em jogos tenham sido montadas sobre infraestrutura computacional: web sites, jogos para computador, em rede ou não, assistentes pessoais digitais e e-mail. Isso significa que, se quisermos alinhar ao aprendizado baseado em jogos o conteúdo que queremos ensinar, os clientes que queremos conquistar, ou objetivos que queremos atingir pelo engajamento de nossos colaboradores, possivelmente estaremos fazendo uso das tecnologias digitais de informação e comunicação. Não surpreende, portanto, que muitas das soluções apresentadas e tidas pelo próprio autor como casos de sucesso foram executadas por equipes multidisciplinares possivelmente consumindo bastante tempo e recursos financeiros.

\section{Jogos digitais e conhecimento científico}

Dentre as diversas formas possíveis de aprendizado baseado em jogos digitais, os casos que são objetos de reflexão neste artigo diferem entre si. Os conceitos mais básicos da teoria quântica, de difícil compreensão até mesmo para alguns professores de física, começam a ser disseminados entre crianças e adolescentes na forma de objetos presentes em jogos de computador e vídeo game. O mesmo acontece com conceitos quanto à complexa estrutura química que compõe as proteínas, com o diferencial de que as soluções encontradas para os desafios propostos aos jogadores são compiladas em um servidor de banco de dados na busca por padrões de resolução que não poderiam ser 
descobertos mais rapidamente lançando-se mão, apenas, de algoritmos de inteligência artificial ou somente pela inteligência humana. É um caso típico de aposta em inteligência híbrida na busca por uma solução. O primeiro caso, de apresentação de conceitos da teoria quântica em jogos digitais, segue mais ou menos a linha de pensamento de uso das redes sociais para ensino de diferentes conteúdos (JULIANI et al. 2012, PEDRO et al. 2015). Entende-se que, se há tanto interesse por parte dos alunos em utilizar redes sociais, por que não estruturar os processos de ensino e de aprendizagem sobre elas? Tais exemplos de uso de jogos para apropriação e avanço no conhecimento científico serão descritos com maior profundidade a seguir.

\subsection{A teoria quântica e o projeto qCraft}

Erwin Schrödinger, físico austríaco e um dos que mais influenciaram no desenvolvimento da teoria quântica, propôs em 1935 o chamado paradoxo do gato em uma tentativa de explicar o conceito da superposição de partículas de uma forma mais facilmente compreensível à comunidade leiga. Isso é importante devido à ligação entre os fenômenos em escala atômica e o universo macroscópico que conhecemos. Maddox (1999) vai mais além ao explicar que, estabelecida esta ligação, podemos descrever quanticamente o motor de um automóvel, o próprio planeta Terra ou mesmo o universo inteiro. Maddox destaca também que o campo no qual a mecânica quântica obteve os melhores resultados nos últimos 50 anos, no estudo das propriedades dos sólidos, só está sendo limitado atualmente pela capacidade dos computadores. O paradoxo do gato de Schrödinger, publicado pelo autor na revista científica alemã Naturwissenschaften em $1935^{1}$, explica que se houver um gato fechado em uma caixa de aço juntamente com uma substância radioativa e um contador Geiger $^{2}$, no período de uma hora é possível que o contador Geiger detecte radiação pelo decaimento ou desintegração atômica da

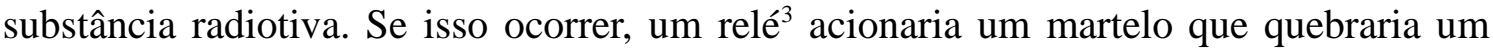
frasco com gás venenoso, o que mataria o gato. Mas há igual probabilidade de não haver decaimento ou desintegração atômica e, assim sendo, o gato continuaria vivo. Tal modelo mental criado por Schrödinger estabelece relação entre o domínio atômico e o mundo por nós perceptível. Enquanto não abrirmos a caixa para saber se o gato está vivo ou morto, ele permanece em um estado "vivo e morto". Ao abrirmos a caixa, determinaríamos o estado do gato como, então, "vivo ou morto". Mas tal determinação só poderia ser feita se e somente se abríssemos a caixa. Para Maddox (1999), com este paradoxo Schrödinger estava questionando se podería haver um estado misto constituído por um gato vivo e um gato morto. Segundo Maddox (1999),

\footnotetext{
A resposta ortodoxa (e inevitável) é que a pergunta foi mal formulada, e não faz nenhum sentido; a transição da escala atômica para a escala macroscópica não é apenas um problema matemático mas deve levar em conta a chamada "seta do tempo". Ainda não se sabe exatamente, porém, de que forma ocorre esta transição. (MADDOX, 1999, p. 98).
}

Percebe-se a complexidade da teoria quântica ainda que seja lançado mão de exemplos, modelos didáticos e metáforas. Para se ter ideia através de outro exemplo, examinemos o conceito da teoria quântica associado à computação. Os profissionais da 
computação conhecem o bit como sendo a menor unidade de informação armazenável, podendo assumir dois valores: 1 ou 0 (carregado ou descarregado, ativado ou desativado). A teoria quântica implementada nos chamados, portanto, computadores quânticos, trabalha com unidades de informação denominadas qubits (contração de quantum bits). Nesse conceito, conforme explicam José et al. (2013),

\begin{abstract}
Diferentemente do computador clássico, no qual um bit pode assumir somente um de dois valores ( 0 e 1$)$, no computador quântico, o qubit possui os dois valores (0 e 1) superpostos. Se o qubit for medido, seu valor irá colapsar para um dos dois valores. Sendo assim, não se pode medir o valor do qubit durante as operações, mas somente ao final dos processos. (JOSÉ et al., 2013, p. 1).
\end{abstract}

Mas como iniciar o aprendizado de complexos conceitos da teoria quântica herdados da física e da química? O projeto qCraft ${ }^{4}$ tem esse objetivo. Conceitos como dependência observacional, superposição e entrelaçamento são ensinados na forma de objetos que compõe um mundo virtual que pode ser construído dentro do jogo Minecraft $^{5}$. Há como objetivo que crianças e jovens possam aprender tais conceitos por analogia, encorajando-os a se dedicar em maior profundidade no tema futuramente (QCRAFT, 2016). A figura 1 mostra uma tela do Minecraft em que se pode ver um bloco sobre o outro. Blocos são usados para construir edificações dentro dos mundos virtuais. O bloco de cima é um bloco quântico. Assim, dependendo da face observada o material que compõe o bloco muda (dependência observacional).

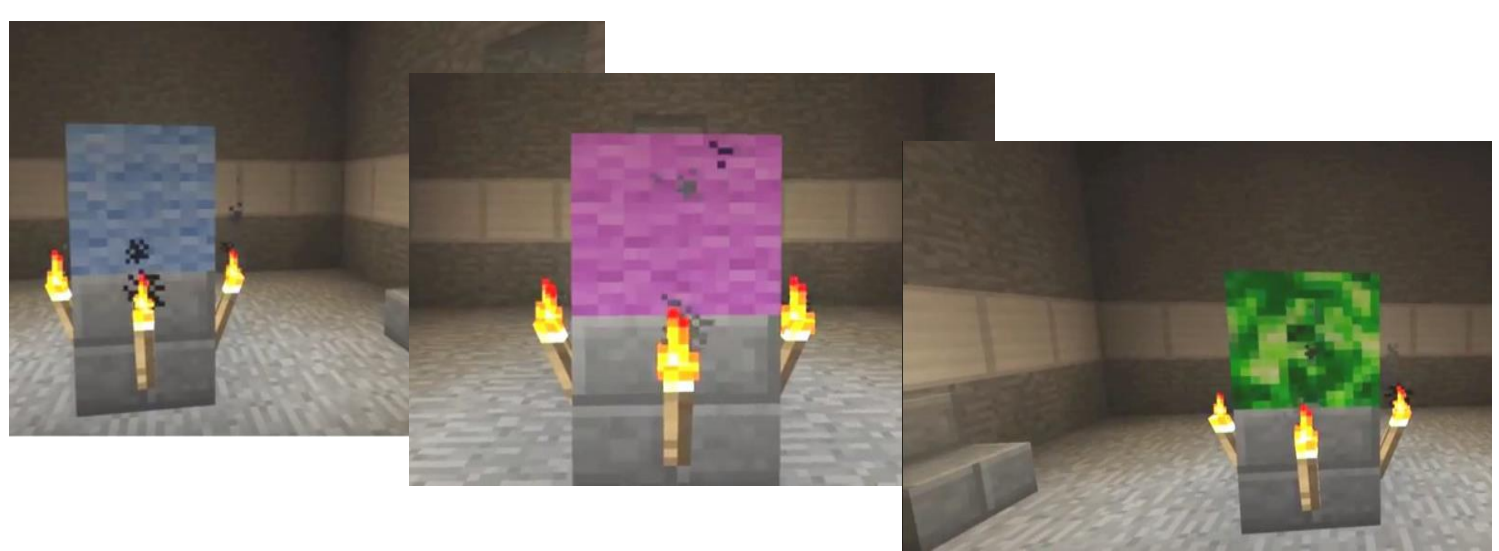

Figura 1 - Observação de 3 faces de um mesmo bloco quântico do Minecraft.

A figura 2 mostra uma caverna escura enquanto o observador contempla determinada face do bloco quântico à esquerda. Ao lado, na mesma figura 2, a mesma caverna brilha devido à mudança de estado do bloco quântico na observação de sua face lateral e principalmente por estarem diversos blocos quânticos separados fisicamente mas entrelaçados ao bloco inicialmente observado (entrelaçamento ou emaranhamento quântico). 

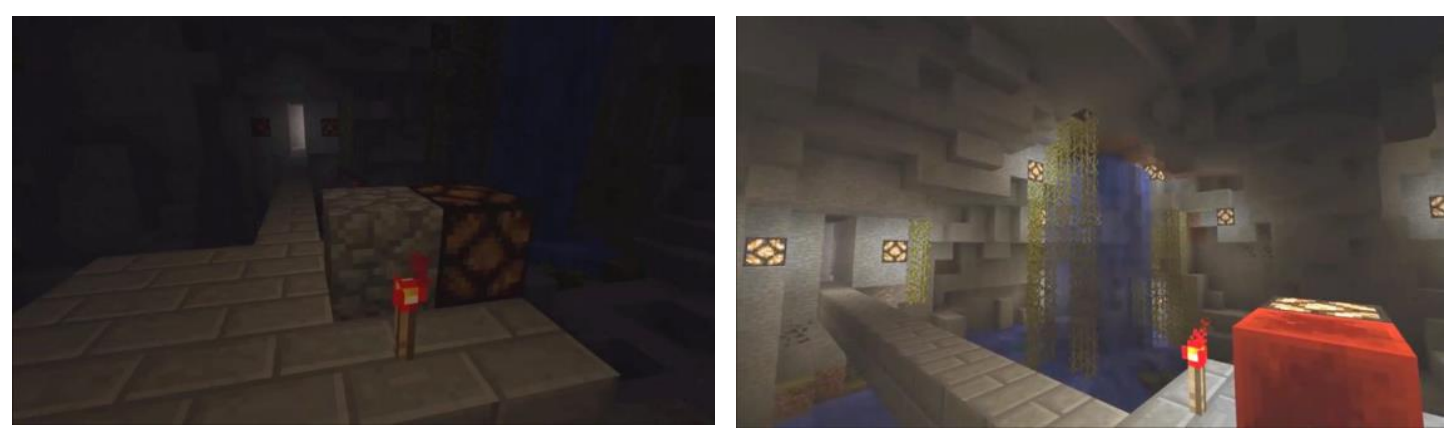

Figura 2 - Caverna que tem sua iluminação alterada devido a presença de blocos quânticos entrelaçados e dependentes do ponto de vista do observador.

\subsection{As complexas cadeias moleculares das proteínas e o projeto Foldit}

O projeto Foldit ${ }^{6}$ disponibiliza um jogo para computador que visa contar com a participação de pessoas ao redor do mundo para encontrar soluções otimizadas de criação de cadeias moleculares que formam as proteínas. O que os jogadores fazem, ainda que não seja tão simples de se entender, é dobrar (do inglês fold, daí o nome do projeto) e desdobrar modelos tridimensionais de proteínas visando encontrar aquela que, entre o maior número possível de combinações, possa consumir a menor quantidade de energia necessária para se manter. A forma como o desafio é apresentado permite que o jogador possa contribuir mesmo não tendo nenhum conhecimento prévio em bioquímica. Para entendermos melhor como funciona, examinemos primeiramente alguns conceitos básicos.

Em termos gerais, as proteínas "cujo nome vem da palavra grega protos, que significa a primeira ou a mais importante, são as biomoléculas mais abundantes nos seres vivos, estando presentes em todas as partes de uma célula". (FRANCISCO JR. e FRANCISCO, 2006, p.1). Tais autores também explicam, em relação às proteínas, que

\footnotetext{
suas unidades constituintes fundamentais são os aminoácidos. Os aminoácidos, por sua vez, são moléculas orgânicas as quais possuem ligadas ao mesmo átomo de carbono (denominado de carbono $\alpha$ ) um átomo de hidrogênio, um grupo amina, um grupo carboxílico e uma cadeia lateral "R" característica para cada aminoácido. Essa cadeia lateral é o que difere os aminoácidos em sua estrutura, tamanho, cargas elétricas e solubilidade em água. (FRANCISCO JR. e FRANCISCO, 2006, p. 1).
}

Proteínas participam, portanto, de quase todos os processos químicos realizados pelo corpo humano: da transformação de alimento em energia, do transporte de nutrientes e oxigênio, da regulagem hormonal, da condução de sinais nervosos cerebrais, isso apenas para citar algumas de suas funções. E por estarem presentes em todos os organismos vivos, são encontradas também em plantas, bactérias e vírus (FOLDIT, 2016). Segundo os criadores do projeto Foldit, uma vez que as proteínas também fazem parte das doenças, também podem representar um caminho para suas 
curas. O trabalho de Khatib et al. (2011) apresentou uma enzima, um tipo de proteína que atua como catalizadora de reações químicas, chamada protease retroviral M-PMV, que possui um papel de fundamental importância no desenvolvimento de um vírus similar ao vírus da AIDS. O formato preciso da estrutura dessa enzima vinha sendo estudado há anos, e com a ajuda de jogadores do Foldit, o modelo da enzima foi construído, surpreendentemente, em poucos dias. Computadores já se dedicavam a esse trabalho ao longo dos últimos anos, porém, a complexidade estrutural das proteínas faz com que o número de combinações possível para encontrar uma solução otimizada seja muito grande. A ideia então, segundo os organizadores do projeto, foi criar uma espécie de inteligência híbrida que faz uso da grande capacidade dos seres humanos em resolver desafios através da intuição, algo que falta aos computadores. Algumas ações tomadas pelo jogador, um ser humano que está vendo efetivamente a cadeia proteica em formato tridimensional, através de sua intuição ou seguindo alguma estratégia, podem servir de atalho para o objetivo final. Os computadores, processando bits algoritmicamente, não têm acesso a esses atalhos, mas complementam as decisões humanas fazendo ajustes finos através de ferramentas acionadas pelo próprio jogador. A figura 3 mostra um exemplo de como a proteína se apresenta na tela principal do Foldit. A figura 4 mostra algumas opções de sintonização da proteína que buscam equilibrá-la. São sintonias finas no modelo feitas pelo computador algoritmicamente.

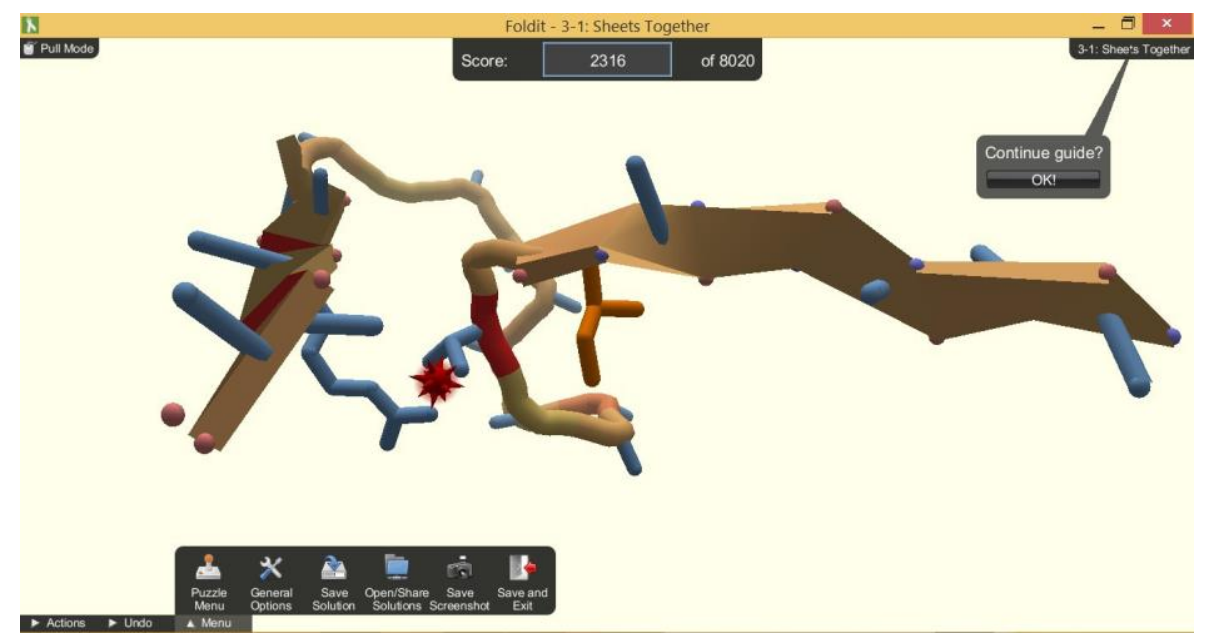

Figura 3 - Tela principal do jogo Foldit mostrando a estrutura de uma proteína.

Algumas outras regras que orientam o desafio são (FOLDIT, 2016):

- Quanto menor o tamanho da proteína, melhor.

- As cadeias laterais de cor laranja são chamadas de hidrofóbicas, e, portanto, devem estar o máximo possível envoltas por átomos da própria proteína para que a água tenha o máximo de dificuldade em alcançá-las.

- As cadeias laterais de cor azul, ao contrário, são chamadas de hidrofílicas, e devem estar com o máximo de exposição possível para que entrem mais facilmente em contato com a água. 
- Como dois átomos não podem ocupar o mesmo lugar no espaço, qualquer encontro desse tipo deve ser revertido e diminui consideravelmente a pontuação. $\mathrm{Na}$ figura 3 tal erro está representado pela bolinha vermelha com espinhos.

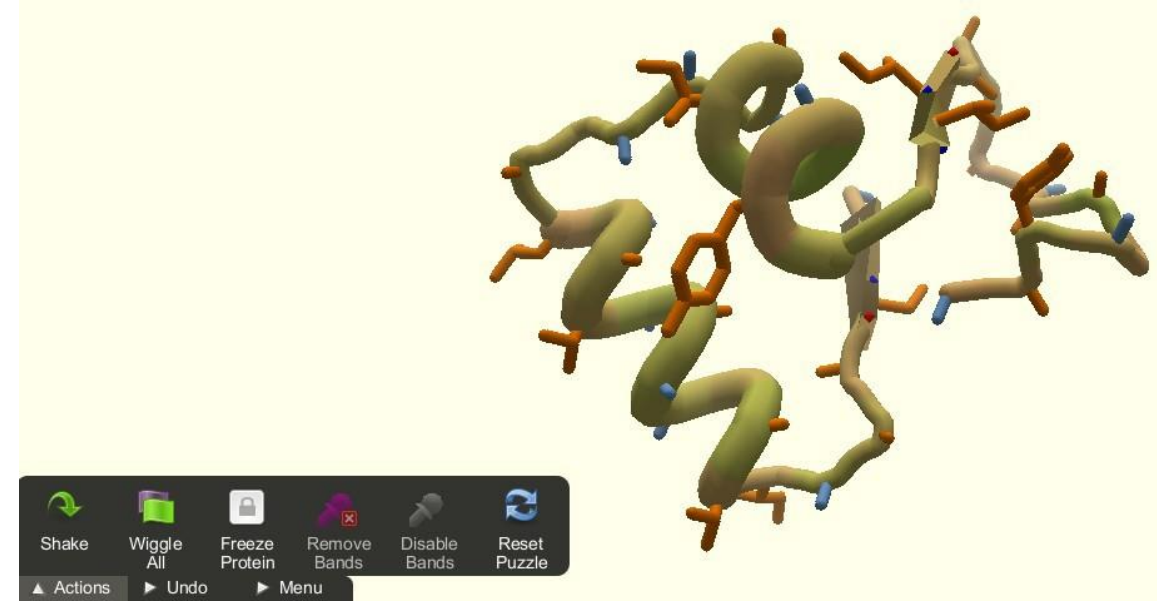

Figura 4 - Tela do jogo Foldit mostrando à esquerda, embaixo, um menu com algumas opções de ajuste aplicáveis à proteína.

\section{Reflexões}

A favor dos dois jogos analisados, é razoável concluir que ambos podem ser usados para fins educativos. Além disso, possibilitam um primeiro contato com conceitos complexos e portanto difíceis de serem ensinados sem recursos eletrônicos. O Foldit vai um pouco além. A solução encontrada pelo jogador ou grupo de jogadores pode ter aplicação prática na criação de drogas sintéticas para a cura de doenças. $\mathrm{O}$ estudo realizado por Carvalho et al. (2012) pesquisou concepções de 133 alunos do ensino médio acerca das proteínas. Uma das perguntas feitas na pesquisa era se o aluno saberia relacionar alguma doença ou deficiência cuja causa estivesse relacionada a alguma proteína específica, não sendo necessário escrever o nome da proteína, somente a doença ou deficiência. Das 194 respostas obtidas, apenas duas apontaram relação entre proteínas e doenças contagiosas (gripe e virose). O contato do estudante com o Foldit, conhecendo ele os objetivos do jogo e suas conquistas científicas recentes, permitiria ampliar sua visão no sentido de perceber a presença das proteínas em outras formas de vida e a relação das mesmas com a cura das doenças, bem como a consequência disso para a sociedade. Ambos os projetos também buscam promover suas formas de inserção nos currículos escolares, ou seja, há orientações que favorecem o aprendizado dos conceitos voltadas aos professores, bem como sugestões de aplicação escalar desses jogos em sala de aula ${ }^{7}$. Por outro lado, não é difícil inferir que algum tipo de concepção alternativa acerca dos conceitos, principalmente no qCraft em relação à teoria quântica, poderá ser produzido pelo estudante-jogador, ainda mais se não houver a figura de um professor mediador que conduza o processo de ensino. Os próprios autores do qCraft reconhecem que ele não foi projetado para ser uma simulação fiel da física quântica, 
entretanto, segundo eles, provê várias analogias que ilustram como os comportamentos quânticos diferem de nossas experiências cotidianas (QCRAFT, 2016). A aposta é que a familiarização contribua para atrair interessados em se dedicar a esses estudos futuramente, ainda que se tenha que reconstruir certos conceitos novamente em outras ocasiões. Também não é difícil perceber a existência de fontes de concepções alternativas no Foldit. Apenas para citar um exemplo, a ferramenta para sacudir a cadeia proteica (botões Shake e Wiggle All mostrados pela figura 4) não existe no mundo real. Existe uma necessidade, por vezes, de ajustes finos na molécula que não seriam possíveis de serem vistos ou manipulados através da interface de um computador, e sim somente com ajuda de um microscópio eletrônico. É aí que entra a varredura algoritmica que o computador aplica ao modelo: uma sintonia fina sobre o que já está pronto e que foi criado através da inteligência e da intuição humanas. Há que se preparar o estudante-jogador quanto à inexistência de ferramentas e botões mágicos que resolvem os problemas reais fora do mundo virtual. Essa seria uma concepção alternativa demasiadamente frustrante. Resultam, por fim, duas conclusões: a primeira é de que o potencial para promover o aprendizado presente nos jogos não pode ser ignorado, e, a segunda, é que parece ser cada vez mais importante a figura do professor atuando como mediador em se tratando do uso de jogos e recursos eletrônicos nos processos de ensino e de aprendizagem.

\section{Notas}

${ }^{1}$ A página da Wikipédia intitulada Gato de Schrödinger, e que está disponível no endereço eletrônico https://pt.wikipedia.org/wiki/Gato_de_Schrödinger, faz ligação ao texto original escrito por Schrödinger intitulado Die gegenwärtige Situation in der Quantenmechanik (A situação atual da mecânica quântica) e publicado na revista Naturwissenschaften, que por sua vez está disponível em http://www.psiquadrat.de/downloads/schroedinger35 katze1.pdf

${ }^{2}$ Contador Geiger é um medidor de radiação ionizante. Recebeu este nome em alusão a um de seus criadores, o alemão Johannes Geiger.

${ }^{3}$ Relé é um interruptor eletromecânico que permite ligar ou desligar um dispositivo eletricamente.

${ }^{4}$ Complemento (ou "mod", no jargão da área, abreviatura de modification) para o jogo Minecraft, teve sua primeira versão pública disponível em 15/10/2013. Acessível em http://qcraft.org . O projeto é coordenado por empresas como o Google e o Instituto de Tecnologia da Califórnia, dentre outras.

${ }^{5} \mathrm{O}$ jogo Minecraft foi oficialmente lançado em 18/11/2011, e está disponível em https://minecraft.net .

${ }^{6}$ Desenvolvido pelo Centro de Ciência dos Jogos e pelo Departamento de Bioquímica da Universidade de Washington. Disponível em https://fold.it/portal . A primeira versão do jogo veio a público em 2008.

${ }^{7}$ Para conhecer sugestões de uso do Minecraft em sala de aula, acessar https://minecraftedu.com . Para conhecer sugestões de uso do Foldit em sala de aula, acessar https://fold.it/portal/node/996074.

\section{Referências bibliográficas}

CARVALHO, J. C.; COUTO, S. G.; BOSSOLAN, N. R. Algumas concepções de alunos do ensino médio a respeito das proteínas. Revista Ciência e Educação, v. 18, n. 4, p. 897-912, 2012. 
EIBEN, C. B. et al. Increased Diels-Alderase activity through backbone remodeling guided by Foldit players. Nature biotechnology, v. 30, n. 2, p. 190-192, 2012. DOI:10.1038/nbt.2109

FOLDIT. The Science Behind Foldit. Disponível em: <https://fold.it/portal/info/about $>$. Acesso em: 04 fev. 2016.

FRANCISCO JR, W. E.; FRANCISCO W. Proteínas: hidrólise, precipitação e um tema para o ensino de química. Revista Química Nova na Escola, v. 24, p. 12-16, 2006.

JOSÉ, M. A.; PIQUEIRA, J. R. C.; LOPES, R. Introdução à programação quântica. Revista Brasileira do Ensino de Física, São Paulo, v. 35, n.1, 2013.

JULIANI, D.; JULIANI, J.; SOUZA, J.; BETTIO, R. Utilização das redes sociais na educação: guia para o uso do Facebook em uma instituição de ensino superior.

RENOTE: Revista Novas Tecnologias na Educação, Porto Alegre, v. 10, N. 3, 2012.

KHATIB, F. et al. Crystal structure of a monomeric retroviral protease solved by protein folding game players. Nature structural \& molecular biology, v. 18, n. 10, p. 11751177, 2011. DOI: $10.1038 / \mathrm{nsmb} .2119$

LEGEY, A. P.; MOL, A. C.; BARBOSA, J. V.; COUTINHO, C. M. Desenvolvimento de jogos educativos como ferramenta didática: um olhar voltado à formação de futuros docentes de ciências. ALEXANDRIA: Revista de Educação em Ciência e Tecnologia, Florianópolis, v. 5, n. 3, nov. 2012.

MADDOX, J. O que falta descobrir: explorando os segredos do universo, as origens da vida e o futuro da espécie humana. Rio de Janeiro: Campus, 1999.

PEDRO, C.; PASSOS, M.; ARRUDA, S. Aprendizagem Científica no Facebook. ALEXANDRIA: Revista de Educação em Ciência e Tecnologia, Florianópolis, v. 8, n. 1, mai. 2015.

PEDROSO, C. V. Jogos didáticos no ensino de biologia: uma proposta metodológica baseada em módulo didático. Anais do IX Congresso Nacional de Educação e III Encontro Sul Brasileiro de Psicopedagogia. Curitiba, 2009. Disponível em: <http://www.pucpr.br/eventos/educere/educere2009>. Acesso em: 08 fev. 2016.

PRENSKY, M. Digital Game-Based Learning: practical ideas for the application of digital game-based learning. St. Paul: Paragon House, 2007.

QCRAFT. A Beginner's Guide To Quantum Physics In Minecraft. Disponível em: <https://www.youtube.com/watch?v=hygLNR_wGPo>. Acesso em: 01 fev. 2016. 